\title{
Influence of various oiling compositions used in conservation on the physical and mechanical parameters of binding leather
}

\author{
Svetlana Khazova $^{1,{ }^{*}}$, Tatiana Velikova ${ }^{1}$, and Tatiana Lisitskaia $^{2}$ \\ ${ }^{1}$ The National Library of Russia, Federal Conservation Center for the Conservation of Library \\ Collections of the National Library of Russia, 191069, Sadovaya street, 18, St. Petersburg, Russia \\ ${ }^{2}$ Saint-Petersburg State Institute of Technology, Department Technology of Microbiological \\ Synthesis, 190013, Moskovsky prospect, 26, St. Petersburg, Russia
}

\begin{abstract}
Protection of leather bindings from the influence of an unfavorable environment is one of the most important tasks of conservation. One way in which this is accomplished is by treating the leather part of an object with an oil or lubricating dressing. The purpose of the work is to study the influence of greases (oiling compositions) of various compositions on leather properties during ageing process (waterabsorbing capacity, hygroscopicity, elasticityand color change). Ten oiling compositions were investigated.
\end{abstract}

\section{Introduction}

Leather and parchment bindings are designed to protect the book block from the harmful effects of the environment. However, bindings of handwritten, rare and valuable books are, in addition, of artistic and historical value and, therefore, require increased attention.

The surface of an animal's skin does not have a simple structure. The skin consists of three layers: the epidermis, dermis, and subcutaneous adipose tissue. Only the dermis is used in leather production. It consists of collagen, elastin and reticulin fibers. Collagen fibers make up about $98 \%$ of the total mass of skin fibers [1,2].

The chemical composition of the leather depends on the type of raw material (animal skins), as well as on the substances included in it during the manufacturing process.

The share of skin proteins accounts for $66.8 \%$ to $91.2 \%$ of the dry residue. The protein composition of the hide is not uniform. Its basis is collagen fibrous protein. In addition to collagen, the skin contains fibrous proteins (elastin, reticulin, keratin) and globular proteins (mucoids, globulins and albumin).

The skin also contains lipids and lipoids; enzymes, hormones and vitamins; carbohydrates: monosaccharides (glucose and galactose), homopolysaccharide (glycogen) and mucopolysaccharides, amino acids. Skin minerals are represented by various salts, mainly sodium chloride, as well as salts of calcium, iron, phosphorus. The amino acid composition of the hide is extremely rich. Of the essential amino acids, glycine, proline, hydroxyproline, glutamic acid, alanine and arginine are the most abundant [2].

*Corresponding author: seti 77@mail.ru 
The skin also contains water. Its content also depends on the relative humidity of the air and the ambient temperature.

During the production process, fatty substances are introduced into the skin to increase its water resistance, softness, and plasticity. The fat content in the skin sometimes reaches $30 \%$.

Acid in the skin can be free, and also be part of the salts and other compounds they contain. During the hydrolysis process, free acid can accumulate in the skin. For chrome tanned and chrome synth tanned leather, the $\mathrm{pH}$ value is in the range of 3.5-5.5.

The skin in small amounts (up to $0.5 \%$ ) contains minerals that have passed from the skin, as well as gets into raw materials during canning and into a semi-finished product in manufacturing processes in the form of salts of sodium, calcium, magnesium, chromium, aluminum, zirconium and others. Vegetable tanned leather contains a tannin mixture of glucose derivatives associated with a different number of digalic and gallic acid residues [3]. The infusion of oak bark and acacia pods, extracts from willow, sumach, gabir have been known since ancient times. To give the bindings a better appearance, the leather was dyed with various dyes of vegetable and animal origin. The leather was often finished to improve the color and embossing with gold, covered with solutions of egg albumin, casein and gelatin, hide glue, flaxseed or Icelandic moss decoction, starch paste [4, 5, 6].

Well made leather, when stored in favorable conditions, is a strong, durable material. There are a large number of old books with perfectly preserved binding. However, over time, like any protein material, the leather is subject to aging. Improper storage conditions accelerate the aging process of the binding leather.

With aging of the leather, there is a decrease in its strength, weight, area, content of water washable substances, shrinkage temperature and an increase in acidity $[7,8,9]$.

Under low air humidity, the leather dries up, the capillaries narrow, as a result of which collagen fibers come closer together, additional bonds are formed between the functional groups of the protein, and hydrogen bonds are strengthened. All this leads to significant stress in collagen and skin shrinkage. Outwardly, this manifests itself in deformation, bending of the binding sides in the direction from the book block. When the air is humid, the leather absorbs moisture and is affected by mold. Excess moisture leads to strong swelling of the leather, collagen becomes looser, its fibers can stick together and exfoliate, due to which the leather is severely deformed, becomes rigid and brittle.

Oxidation of tanning agents, which is accompanied by the breakdown of the sugars, fats, etc. present, causes the appearance of free organic acids. As a result of their action on the tanned fiber, its fragility increases, which leads to a decrease in the resistance of the leather to mechanical stress.

The formation of organic acids and their corrosive effect on the leather of the bindings also occurs as a result of the oxidation of fatty components. Free acids (sulfuric, acetic, tartaric, etc.) can appear in bookbinding leathers as a result of the use of certain reagents by manufacturers when decorating bindings, marble finishing. This process is favoured by sulphur dioxide and nitrogen dioxide, present in polluted atmosphere. These gases contribute to the acid hydrolysis of leather and finally to advanced degradation of museum leather artefacts, in time $[10,11,12]$.

Dusty air also has a destructive effect on the leather. Dust particles are not inert, they contain active centers that intensively absorb water, sulfur dioxide, and adsorb fatty substances of the leather. Dust particles promote further accumulation and development on the bindings. In addition, dust is a carrier of bacteria and micromycete spores and a source of food for them.

There are two types of aging: chemical, associated with damage of the structure of the leather, and physical, which is usually expressed in damage of the outer layer and exposure of the tough fibers of the lower layers. 
High-quality leather - both vegetable-tanned leather and chrome-tanned one - can be kept for a long time when it is dry. However the physicochemical processes accelerating its ageing, i.e. the sharp decrease of water and fat quantity in leather, takes place when the humidity of ambient air is low.

They partly escaped out of leather directly in the form of fats or in the form of oxidation products and partly are removed mechanically with dust on which they are sorbed. Water loss by leather is a reversible process and with increasing air humidity leather absorbs equilibrium amount of water again. Fat loss is irreversible, so it is necessary to fill it with oiling in leather bindings. One way in which this is accomplished is by treating the leather part of an object with an oil or lubricating dressing $[13,14]$.

Various oiling compositions giving softness and plasticity to leather material are used for that purpose. For the preservation of leather, a variety of substances and complex compositions are proposed, consisting of animal fats, waxes, mineral oils: hoof oil, watch oil, castor oil, liquid paraffin, lanolin, petroleum jelly, spermaceti $[15,16]$. Wax as a part of grease gives it additional hydrophobic properties protecting leather against humidity drops in the ambient air of book depository. Comprehensive investigation of recommended agents is necessary to use new methods in the field of book conservation.

\section{Materials and methods}

The purpose of the work is to study the influence of greases (oiling compositions) of various compositions on leather properties during ageing process (water-absorbing capacity, hygroscopicity, elasticity and color change).

Ten oiling compositions were investigated. Four of them were prepared according to formulations reported in the literature, two of them were prepared on the basis of clock oil, they were developed and used at the National Library of Russia for a long time, and four new greases were created at the laboratory at present.

As a test material, we used chrome-tanned leather samples of four sorts: cattle leather black (CL-1), light brown (CL-2), with nitro-lacquer coating, light brown pigskin (PS-1), and gray pigskin. (PS-2). The object for assessing the variations of physical and mechanical properties (moisture capacity, elasticity and hygroscopicity) was black cattle leather (CL1), since this is the leather most often used in modern restoration of bindings. The large size of the hide allows testing in the required amount multiplicate repetitions. Six different sorts of modern leather and binding leather from the 18th century were used to study the effect of preservation lubricants on overall color difference.

The effect of conservation lubricants was evaluated according to the following parameters:

-elasticity (maximum elongation);

- moisture capacity;

-hygroscopicity;

-color change (general color difference).

The moisture content of the leather was determined according to Russian State Standard GOST 938.24-72. The samples were immersed in water for 2 hours and 24 hours and the amount of absorbed water was determined by the gravimetric method.

The hygroscopicity was determined according to Russian State Standard GOST 897178. The samples were placed in a desiccator with a relative humidity of $95 \%$ for 16 hours and the amount of absorbed moisture was determined by the gravimetric method.

Changes in the physical and mechanical properties of leather samples were determined by tensile strength (maximum elongation) using a Hounsfield device. 
Table 1. The oiling compositions.

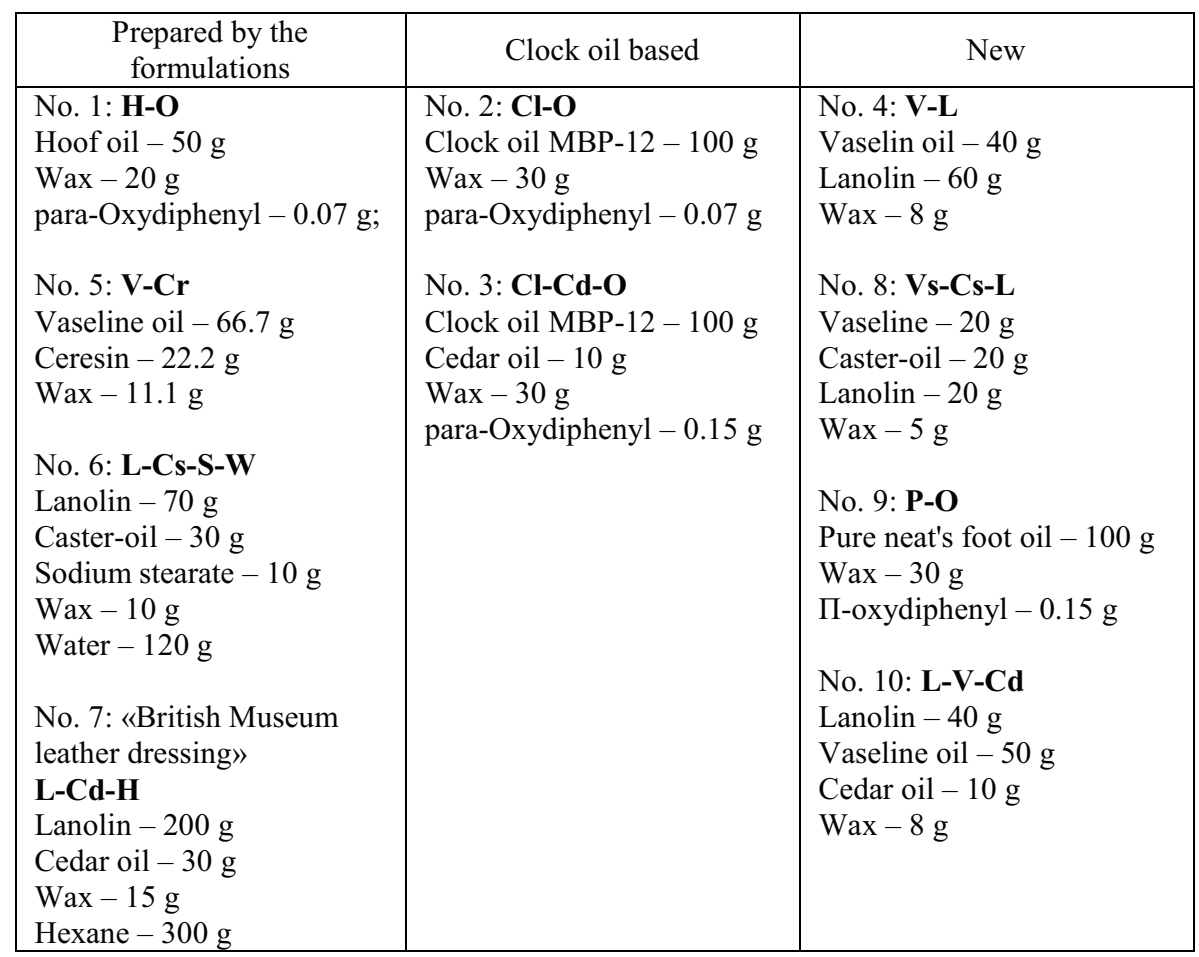

The obtained values of mechanical characteristics were compared with the values obtained for the control samples (untreated with conservation lubricants). The change in the physical and mechanical characteristics of the materials under study was determined by the formula:

$$
N i=(N o / N k) \times 100 \%,
$$

where No - the index of the test sample,

$\mathrm{Nk}$ - the index of the control sample.

The values of the color coordinates CIE L $* a * b *$ of leather samples were determined by the spectrocolorimetric method for assessing small color differences in an equal-contrast three-dimensional system, and based on the obtained values, the value of the total color difference $\Delta \mathrm{E}$ was calculated using the formula (2). All optical characteristics were measured on an Elrefo instrument with a $34 \mathrm{~mm}$ aperture.

$$
\Delta E=\sqrt{\Delta L^{2}+\Delta a^{* 2}+\Delta b^{* 2}} \sqrt{\Delta L^{2}+\Delta a^{* 2}+\Delta b^{* 2}}
$$

where $\Delta \mathrm{E}$ is the total color difference,

$\mathrm{L}$ - lightness,

a * — the index of the red-green component,

$\mathrm{b} *$ — the index of the yellow-blue component.

To assess the physical and mechanical properties of the leather treated with the investigated biocides and oiling compositions, artificial aging was carried out during storage under natural conditions. 
Accelerated thermal and moisture artificial aging of paper samples was carried out for 360 hours in a Binder chamber (Germany) at a temperature of $45^{\circ} \mathrm{C}$ and a relative humidity of $80 \%$.

Dry aging was carried out in a thermostat at a temperature of $80{ }^{\circ} \mathrm{C}$ for 180 hours.

For light aging of leather samples, a $220 \mathrm{~V}$ mercury-quartz lamp was used for 25 hours.

The fungal resistance of leather samples treated with oiling compositions and biocides was determined by the disk diffusion method. Skin samples were placed on the surface of an agar medium contaminated with a spore suspension of Aspergillus ustus (Bainier) Thom \& Church.

Petri dishes with infected samples were incubated at $26 \pm 2{ }^{\circ} \mathrm{C}$. After 14 days, fungal resistance was assessed by the presence of a zone of inhibition, which was determined as the diameter of the zone of no micromycete growth from the center of the sample.

\section{Results}

New chrome leather samples were investigated. Protection rate of leather bindings in case of getting into water was determined by the variation of the water-absorbing capacity of leather after processing with test oiling compositions. Water-absorbing capacity was determined by the quantity of moisture absorbed by leather during two and 24 hours when putting samples into distilled water.

Water-absorbing capacity of the leather of control samples in 24 hours was $170 \%$; leather processed with grease based on clock oil and cedar oil had the same waterabsorbing capacity (Cl-Cd-O) (Fig.1). Water-absorbing capacity of leather processed with greases based on hoof oil (H-O) and clock oil (Cl-O) increased insignificantly, $177 \%$ and $174 \%$ respectively, so they will not be able to protect leather against humidity drops.

All other oiling compositions decreased the water-absorbing capacity of material to a variable degree: most of all it was in leather processed with grease based on lanolin, vaselin oil, and cedar oil (L-V-Cd - $139 \%)$.

Degree of water-absorbing capacity of binding leather is a very significant value in the case of emergency situation, when documents can turn out to be partly or fully in water, bindings will be protected against water for longer time as compared to unprocessed ones.

Hygroscopicity is a very important indicator as it characterizes the ability of oiling compositions to protect the binding leather against humidity drops in the room. Hygroscopicity was determined by gravimetric method, by the quantity of moisture, which can be absorbed by leather placed above water for 16 hours.

Hygroscopicity of the leather of control samples was $15.5 \%$ (Fig. 2). All the greases investigated decreased the hygroscopicity of leather: about $1 \%$ of control indicator on average. The lowest hygroscopicity is observed in leather processed by oiling composition based on ceresin (V-Cr), it is $12.7 \%$.

During natural ageing (on the long storage of books) the change of physico-mechanical properties of leather takes place: it becomes more rigid, stronger, and smaller by volume, its hygroscopicity decreases. Three methods of accelerated artificial ageing were used to simulate the natural ageing: heat and humidity ageing (during 360 hours in the chamber «Binder» at the temperature of $45^{\circ} \mathrm{C}$ and relative humidity of $80 \%$ ), dry (at the temperature of $80^{\circ} \mathrm{C}$ during 180 hours) and ultraviolet ageing (under mercury quartz lamp with the power of $220 \mathrm{~V}$ during 25 hours).

Hygroscopicity of leather decreased most of all (up to $11.4 \%$ ) after heat and humidity ageing and least of all (up to $14.11 \%$ ) after dry ageing.

After heat and humidity ageing the hygroscopicity of the leather of all samples decreased insignificantly. The largest variation was observed in control samples (by $4 \%$ ) 
and in samples processed with oiling composition Vs-Cs-L (by $4.3 \%$ ) and L-Cd-H (by $4 \%$ ).

Both after dry ageing and after ultraviolet ageing the hygroscopicity of leather processed with oiling compositions changed less than in control samples and samples after heat and humidity ageing. Change of hygroscopicity in samples of processed leather was about $1 \%$ on average.

The main task of oiling compositions is to have a conservation effect (to keep physical and mechanical characteristics) for a long time. Hygroscopicity of leather processed with oiling compositions based on lanolin as well as vaselin oil and cedar oil L-V-Cd changed least of all after three kinds of ageing. This parameter decreased by $2 \%$ after heat and humidity ageing and practically did not change after dry and ultraviolet ageing.

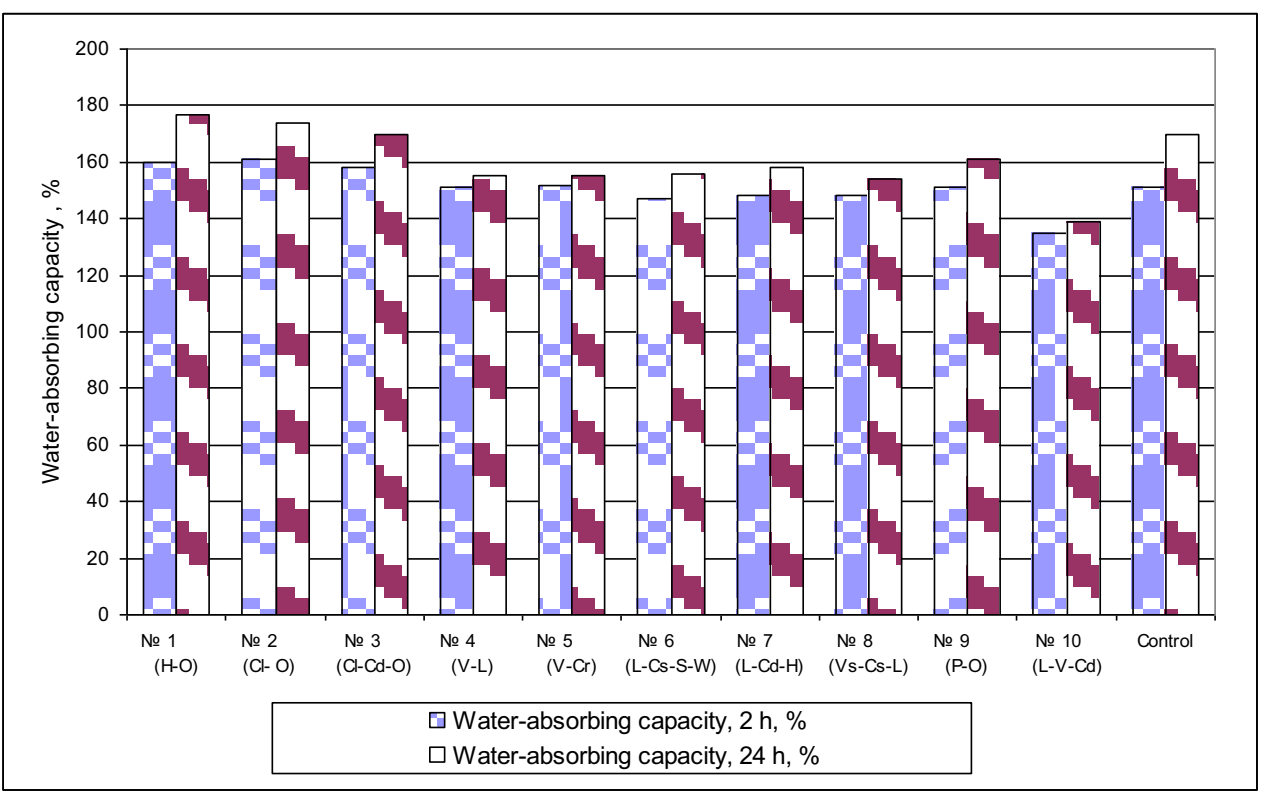

Fig. 1. Water-absorbing capacity of the leather treated with oiling compositions.

The best results for the influence of the ageing of three kinds on leather processed with oiling compositions are obtained for greases based on ceresin $(\mathrm{V}-\mathrm{Cr})$ and ones based on lanolin as well as vaselin oil and cedar oil (L-V-Cd).

Elasticity change of leather processed with greases before and after ageing was also determined for the comprehensive assessment of the oiling influence on bindings.

All the oiling compositions increased leather elasticity on average by $11 \%$ (Fig. 3). The largest stretching was in leather processed with oiling compositions based on ceresin (V$\mathrm{Cr}$ ). Leather elasticity increased insignificantly after processing with oiling compositions based on clock oil (Cl-O), castor oil (L-Cs-S-W and Vs-Cs-L) and «British Museum leather dressing» (L-Cd-H). Leather elasticity increased on average by $10 \%$ after processing with oiling compositions based on lanolin (V-L and L-V-Cd).

Elasticity of leather processed with oiling compositions after heat-and-humidity ageing and dry ageing was also higher than in control samples. All the greases investigated after ageing carried out in three methods protected leather efficiently. Exception was the oiling compositions based on lanolin and castor oil (L-Cs-S-W): stretching of leather processed with that oiling composition after dry ageing was lower than in control samples on average by $9 \%$. 


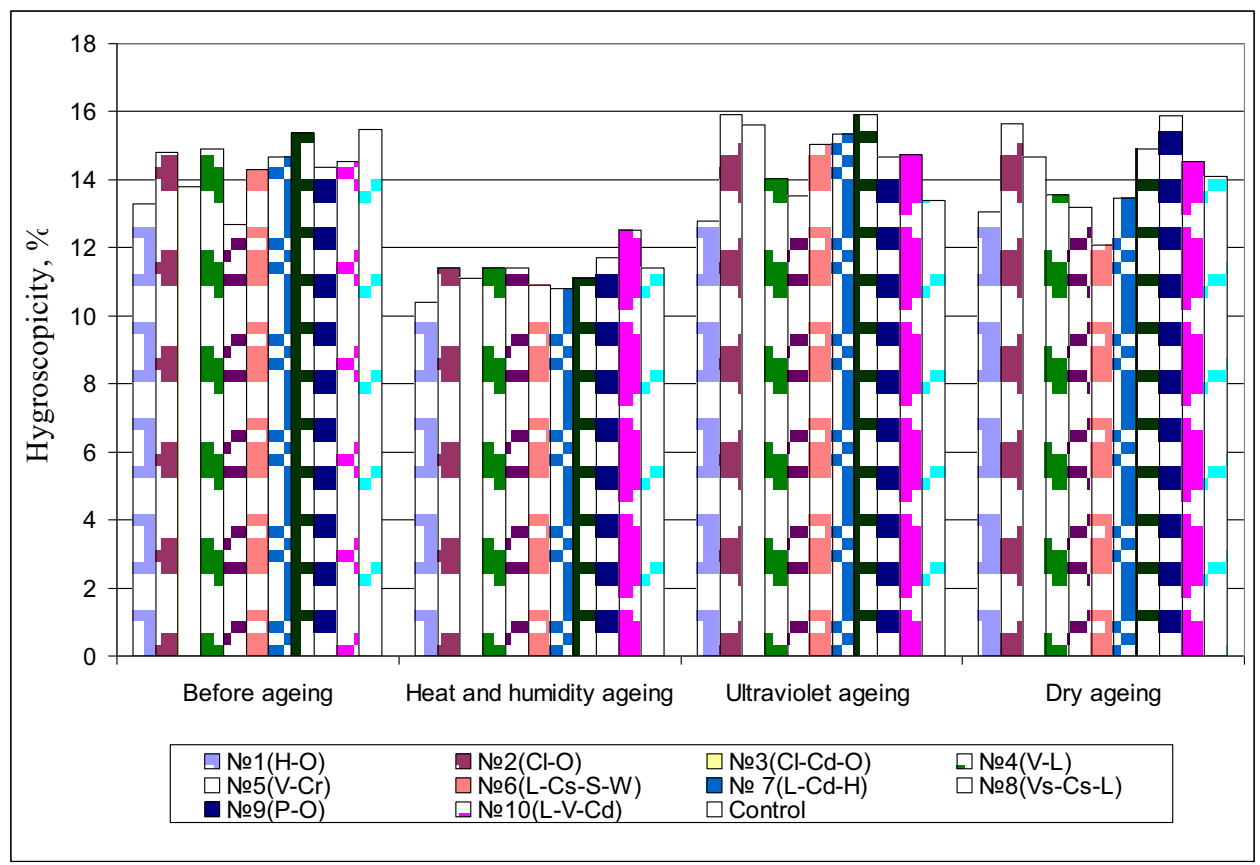

Fig. 2. Hygroscopicity of leather processed with oiling compositions, before and after ageing.

Most oiling compositions after ultraviolet ageing have the least conservation effect. After processing with greases based on clock oil (Cl-Cd-O), lanolin and castor oil (L-Cs-S$\mathrm{W}$ and V-Cs-L), as well as «British Museum leather dressing» (L-Cd-H), leather elasticity decreased as compared to control samples on average by $5 \%$. Leather elasticity after processing with oiling compositions based on clock oil (Cl-O) and pure neat's foot oil (P$\mathrm{O})$, lanolin and vaselin oil (V-L), lanolin, vaselin oil and cedar oil (L-P-Cd) did not differ practically from control unprocessed samples of leather. Only two greases - based on hoof oil (H-O) and ceresin ( $\mathrm{V}-\mathrm{Cr})$ - promoted leather elasticity improvement.

After carrying out the artificial ageing in three methods, it is shown that leather elasticity after processing with five oiling compositions increased as follows: for agent based on ceresin ( $\mathrm{V}-\mathrm{Cr}$ ) on average by $18 \%$, for agent based on pure neat's foot oil (P-O) by $11 \%$, for agent based on hoof oil (H-O) and for agents based on lanolin, vaselin oil, and cedar oil (V-L and L-V-Cd) by $10 \%$.

Basing on the data of the investigation carried out, i.e. data on the influence of greases on water-absorbing capacity, hygroscopicity, and elasticity of leather, including after artificially accelerated ageing in three methods, we can recommend three oiling compositions based on ceresin (V-Cr), as well as based on lanolin and vaselin oil (V-L and $\mathrm{L}-\mathrm{V}-\mathrm{Cd}$ ) for processing leather bindings.

Treatment with fatty compounds almost always leads to darkening of the leather. The degree of change depends on the dressing, processing of the leather, its coating and color.

Six different types of leather were processed: modern leather in various colors and finishes, 18th century leather.

According to the recommendation of Russian State Standard GOST R ISO 105-A02-99, the following criteria were adopted for the overall color difference of the skin: $\Delta \mathrm{E}<0.8-$ no visible color difference between the tested sample and the control is observed, with $\Delta \mathrm{E}$ $<1.7$, the color change is very weak, hardly distinguishable, at $\Delta \mathrm{E}$ from 1.7 to 2.5 , the color changes are weak, insignificant at $\Delta \mathrm{E}$ from 2.5 to 3.4 - the changes are moderate, barely perceptible to the naked eye, at $\Delta \mathrm{E}>3.4$ there is a visible color change, at $\Delta \mathrm{E}>6,8$, the 
color change is clear, visible, easily distinguishable, with $\Delta \mathrm{E}>13.6$, the color change of the leather is significant, strongly pronounced.

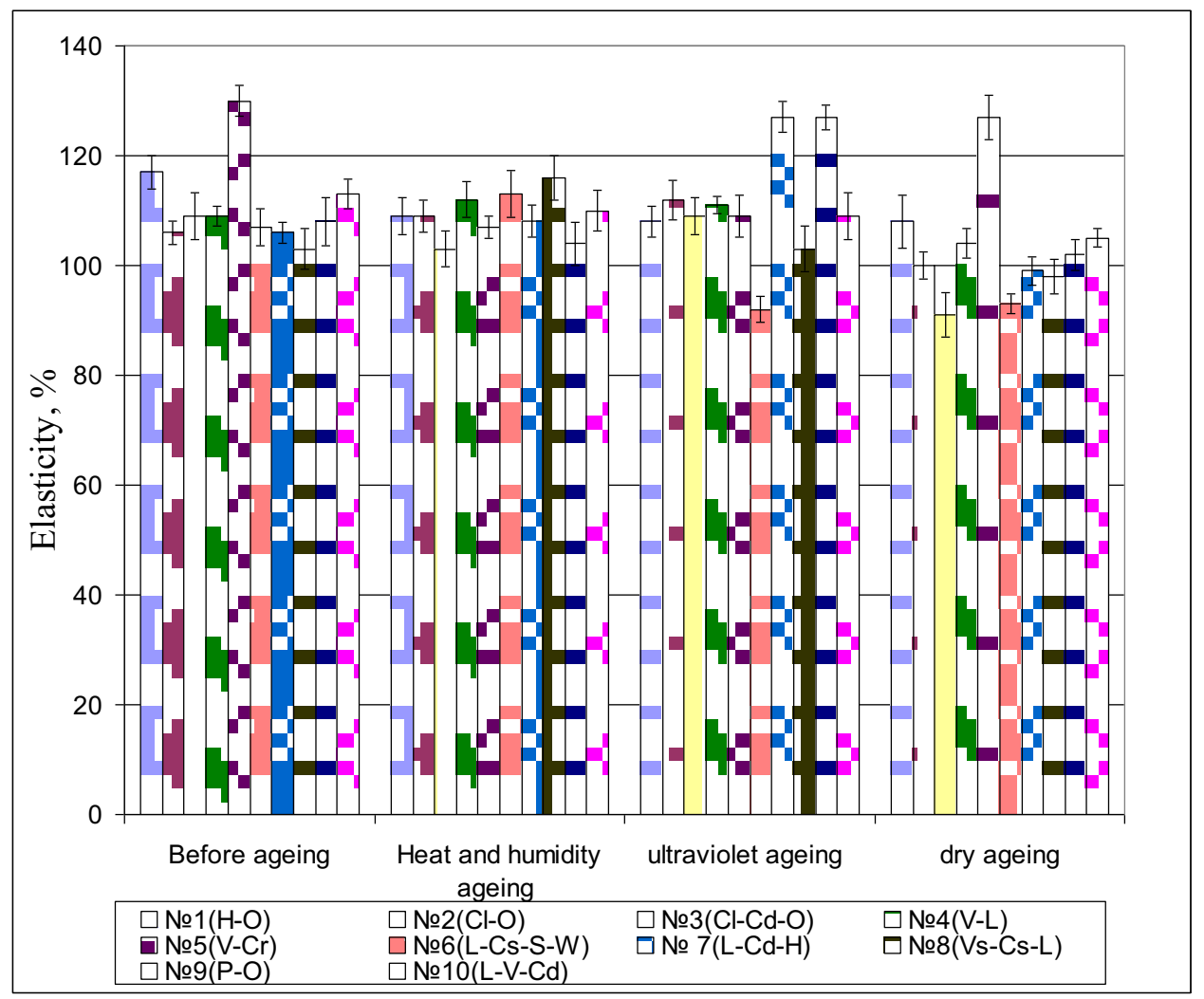

Fig. 3. Elasticity of leather processed with oiling compositions, before and after ageing.

Leather color changed in different ways under the influence of greases (Table 2). A significant darkening of the color occurred under the action of all greases in leathers that did not have a nitro-varnish coating and leathers were dyed in light colors. Slightly influenced by the treatment with oiling compositions on leathers of a darker shade, finished and modern leather with a nitro-lacquer coating.

Table 2. Discoloration of skin treated with oiling compositions.

\begin{tabular}{|c|c|c|c|}
\hline \multirow{2}{*}{ Lether sort } & \multicolumn{3}{|c|}{ Oiling compositions } \\
\cline { 2 - 4 } & № 4 (L-V) & № 5 (V-Cs) & № 10 (L-V-Cd) \\
\hline CL-1 & 0,09 & 0,17 & 0,07 \\
\hline CL-2 & 1,92 & 1,65 & 1,27 \\
\hline PS-1 & 10,73 & 10,92 & 7,94 \\
\hline PS-2 & 13,43 & 10,32 & 7,37 \\
\hline $\begin{array}{c}\text { 18th century } \\
\text { leather(marble) }\end{array}$ & 6,99 & 9,09 & 2,85 \\
\hline $\begin{array}{c}\text { 18th century leather } \\
\text { (brown) }\end{array}$ & 9,61 & 6,85 & \\
\hline
\end{tabular}

Oiling compositions No. 4 (L-V) caused significant darkening in all skins examined, with the exception of modern coated leather. The smallest effect on the color of the leather 
was produced by oiling compositions No. 10 (L-V-Kd). Color change of leather treated by this oiling compositions was minor.

Leather lubricated with fatty substances is a more favorable environment for the growth of micromycetes than untreated leather. Also, oiling compositions reduce the hydrophobicity of the leather, as the wax, which is part of the grease, creates a film on the leather surface. And since the investigated biocides are water-soluble, there is a possibility of a decrease in the effectiveness of the biocidal action of drugs on oiling compositions. It is also possible to change the properties of biocides when mixed with fatty compounds. Therefore, the next stage of the study was to determine the effectiveness of oiling compositions with biocides.

Leather samples were treated in a different sequence with the Rocima GT biocide and the oiling composition currently used in the NLR - No. 4 (V-L), as well as their composites (oiling compositions containing the Rocima GT biocide at a concentration of $5 \%$ ). The effectiveness of the treatment was assessed by the amount of carbon dioxide released during the growth of micromycetes on the leather. As a test culture, Aspergillus ustus was used, as one of the most common bindings of micromycetes on the leather, and also as an active destroyer of the leather (Table 3).

Micromycetes developed more actively on 18th century leather than on modern leather. Also, fungal growth on leather treated with oiling composition would be higher than on untreated leather.

The leather, treated in any sequence with oiling composition and biocides, as well as composites, did not undergo any biodamage even for 40 days.

Consequently, treatment by oiling compositions does not reduce the effectiveness of biocidal drugs. And composites have not only a preservative effect and a biocidal effect, which will protect the leather from microbiological damage in the event of an emergency for a long time.

Table 3. Determination of the respiratory activity of Aspergillus ustus during growth on leather treated with biocides before and after aging.

\begin{tabular}{|c|c|c|c|}
\hline Material & Treatment 1 & Treatment 2 & $\begin{array}{c}\mathrm{CO}_{2} \\
\text { concentration, \% }\end{array}$ \\
\hline \multirow{5}{*}{ Modern leather } & - & - & 3,50 \\
\hline & $\begin{array}{l}\text { Oiling composition } \\
\text { No. } 4(\mathrm{~L}-\mathrm{V})\end{array}$ & - & 6,99 \\
\hline & $\begin{array}{l}\text { Oiling composition } \\
\text { No. } 4 \text { (L-V) }\end{array}$ & Rocima GT (5 \%) & 0,48 \\
\hline & Rocima GT (5 \%) & $\begin{array}{c}\text { Oiling composition } \\
\text { No. } 4 \text { (V-L) }\end{array}$ & 0,37 \\
\hline & $\begin{array}{c}\text { Composite No. } 4(\mathrm{~L}-\mathrm{V})+ \\
\text { Rocima GT }(5 \%)\end{array}$ & - & 0,38 \\
\hline \multirow{5}{*}{ 18th century leather } & - & - & 13,20 \\
\hline & $\begin{array}{l}\text { Oiling composition } \\
\text { No. } 4(\mathrm{~L}-\mathrm{V})\end{array}$ & - & 15,22 \\
\hline & $\begin{array}{l}\text { Oiling composition } \\
\text { No. } 4 \text { (L-V) }\end{array}$ & Rocima GT (5 \%) & 0,23 \\
\hline & Rocima GT (5 \%) & $\begin{array}{l}\text { Oiling composition } \\
\text { No. } 4(\mathrm{~L}-\mathrm{V})\end{array}$ & 0,30 \\
\hline & $\begin{array}{c}\text { Composite No. } 4 \\
(\mathrm{~L}-\mathrm{V})+\text { Rocima GT }(5 \%)\end{array}$ & - & 0,26 \\
\hline $\begin{array}{c}\text { Control (modern } \\
\text { leather) }\end{array}$ & - & - & 0,09 \\
\hline $\begin{array}{c}\text { Control (18th century } \\
\text { leather) }\end{array}$ & - & - & 0,08 \\
\hline
\end{tabular}




\section{Conclusions}

Studies have shown that three oiling compositions can be recommended for stabilization and preservation for finished leathers or leathers with an external dye layer or: based on ceresin (No. $5 \mathrm{~V}-\mathrm{C}$ ), based on lanolin and vaseline oil (No. $4 \mathrm{~L}-\mathrm{V}$ and No. $10 \mathrm{~L}-\mathrm{V}-\mathrm{Kd}$ ). Oiling compositions should be used with caution for light-colored pigskins that do not have an external dye layer. The least effect on the color of such leathers is exerted by a lubricant based on lanolin and vaseline oil No. $10 \mathrm{~L}-\mathrm{V}-\mathrm{Cd}$.

Treatment with oiling composition does not affect the effectiveness of the Rocima GT biocide, this biocide also prevents the growth of micromycetes on the leather, while storing it for a week in conditions of high humidity, it is important for emergency situations when it is not possible to dry the document quickly.

\section{References}

1. R. Larsen, Ph.D. Thesis, University of Copenhagen, The Royal Danish Academy of Fine Arts, School of Conservation, Copenhagen (1995)

2. M. Kite, R. Thomson, Conservation of leather and related materials (Elsevier, Oxford, 2006)

3. C. Carsote, E. Badea, I. Caniola, S. Paunescu, M. Lupas, C. Sendrea, L. Miu, Revista de Chimie Bucharest Original Edition 71(3), 51-58 (2001) DOI: 10.37358/RC.20.3.7973

4. E.H. Windhum, J.P. Gordon, A. Seymour-Jones, C. Davenport, F.G. Williamson, Leather for libraries (London, 1905) http://www.survivorlibrary.com/library/leather for libraries 1905.pdf

5. L. Falcão, M.E.M. Araújo, Journal of Cultural Heritage 12, 149-156 (2011) doi.org/10.1016/j.culher.2010.10.005

6. L.Falcao, M.E.M.Araujo, Molecules 23, 1081(2018)DOI: 10.3390/molecules23051081

7. V. Dirksen, Journal of Conservation and Museum Studies 3, 6-10 (1997)

8. A. Bacardit, M. Jorba, J. Font, L. Olle, JALCA 107(6), 179-185 (2012)

9. L. Olle, M. Jorba, J.C. Castell, J. Font, A. Bacardit, 31st IULTCS Congress (2011)

10. H.A.B. van Soest, T. Stambolov, P. Hallebeek, Studies in Conservation 29, 21-31 (1984) DOI: $10.2307 / 1505940$

11. M. Pruneanu, I. Bucişcanu1, E. Ardelean, N. Melniciuc-Puică, European Journal of Science and Theology 8(4), 225-232 (2012)

12. R. Larsen, Chimia 62(11), 899-902 (2008) DOI: 10.2533/chimia.2008.899

13. R. Larsen, J. Wouters, C. Chahine, P. Brimblecombe, C. Calnan, Research report 6, 189-202 (1996)

14. R.J. Thomson, J. Am. Leather Chem. As. 97(8) (2002)

15. D.H. Tuck, Oils and Lubricants Used on Leather, Leather Conservation Centre (1983)

16. J.R. Blockey, The Application of Oils and Greases to Leather, General Books LLC (2010) 